\title{
A conjuntura atual e o enfrentamento ao coronavírus: desafios ao Serviço Social
}

The current situation and the fight against the coronavirus: challenges to Social Work

\author{
Maria Carmelita Yazbek ${ }^{a}$ \\ (D) https://orcid.org/0000-0002-4785-472X \\ Maria Inês Bravob \\ (D) https://orcid.org/0000-0003-2347-0518 \\ Maria Liduína de Oliveira e Silvac \\ (1) https://orcid.org/0000-0002-7904-4836 \\ Maria Lúcia Martinellia \\ (D) https://orcid.org./ 000.0001.9124.2846
}

Chegamos ao número 140 da Revista Serviço Social \& Sociedade em um contexto bastante adverso, caracterizado por uma pandemia que desafia a sociedade brasileira e também a revista na tarefa de manutenção de sua qualidade e na interlocução com a realidade do país, tarefa que vem desempenhando desde sua emergência como periódico.

É fundamental lembrar que 1979, quando tem início a Revista, foi o ano do III Congresso Brasileiro de Assistentes Sociais em um cenário emblemático, de lutas que enfrentam a presença do conservadorismo na profissão explicitando seu "compromisso com a classe trabalhadora, com a renovação e com a democracia na perspectiva da socialização do poder político, da riqueza e da cultura” (Yazbek et al., 2016, p. 347). 
Nesses exatos 41 anos de publicações, a Revista tem sido fonte de referência histórica e de conhecimento para a categoria profissional e científica, mantendo instigantes interlocuções com o Serviço Social brasileiro, as ciências sociais aplicadas e humanidades, constituindo-se em um espaço plural e democrático.

Mais do que um periódico, vem sendo um verdadeiro marco na história do Serviço Social brasileiro, pois tem acompanhado seu processo de maturação intelectual e política em interlocução com a realidade.

Nesta edição, elaborada em um contexto de crise estrutural do capital, que cresce em seu caráter ultraliberal, ultraconservador e predatório, em que se perdem direitos e crescem vertiginosamente desproteções, ameaças à vida representadas pelo coronavírus apenas escancararam a vergonhosa desigualdade da sociedade brasileira, explicitando contradições de um capitalismo em processo de reestruturação produtiva e sujeito à lógica das finanças.

Na realidade, o país já vinha em uma escalada de acirramento de suas contradições mais profundas, decorrentes da crise do capital, agravada pela guinada à direita no âmbito da política, cuja objetivação mais eminente foi a eleição de Jair Messias Bolsonaro para o governo federal em 2018. Ainda que o avanço de grupos de ultradireita e fascistas seja um fenômeno mundial, cabe analisar as particularidades brasileiras que sustentam o chamado neoconservadorismo e como este se combina e mescla-se a um processo de radicalização do neoliberalismo no âmbito da economia.

Meszáros (2002) havia explicitado que o capitalismo contemporâneo é globalizante e seu sociometabolismo evidencia as formas mais bárbaras de produção e reprodução social, tão bem evidenciadas nesse contexto de crise do capital e associadas pela pandemia da covid-191,

1 O estado de pandemia de coronavírus foi declarado pela Organização Mundial da Saúde (OMS) em 11 de março de 2020. É uma pandemia em curso de covid-19, uma doença respiratória aguda causada pelo coronavírus da síndrome respiratória aguda grave 2 (SARS-CoV-2). 
quando sobressai a intensificação do trabalho aprofundada com a superexploração no capitalismo, acirrando expressões da questão social com o crescimento do desemprego, da informalização, da precarização do trabalho e das medidas regressivas de direitos.

Nos anos recentes, o movimento do capital para encontrar as melhores condições para a reprodução ampliada vem desenvolvendo o processo de integração de forma mais acirrada entre o capital estrangeiro e as economias nacionais, que culmina no aprofundamento da dependência.

A questão social intensificada pela relação trabalho/capital foi aprofundada com a superexploração do trabalho, no capitalismo dependente, acirrando-se a substituição do trabalho vivo pelo trabalho morto, ampliando o exército industrial de reserva e a precarização das condições de vida e de trabalho da classe trabalhadora. O que se evidencia é que a classe trabalhadora passa a se submeter a condições de trabalho cada vez mais instáveis e precarizadas, com baixos salários, sem respaldo de direitos trabalhistas e vínculos empregatícios formais.

No início de 2020, a pandemia encontrou o país em meio a uma profunda crise, caminhando para o retorno ao mapa da fome, com gastos públicos congelados e, consequentemente, mais precarização das políticas sociais e privatização de serviços, com uma reforma da Previdência que aniquila direitos do trabalho. O negacionismo da doença pelo governo federal faz parte de uma estratégia governamental, mesmo que isso custe muitas vidas, ou seja, tem um propósito político que inclui lidar com a doença, promovendo praticamente o genocídio dos mais frágeis.

Discutir os impactos da pandemia na relação entre Serviço Social e políticas sociais - como educação, saúde, assistência social e mundo do trabalho - revela a lógica perversa do governo que encarna e reproduz os interesses da sociedade do capital; revela ainda como esta se mantém fortalecida, enquanto o sofrimento e o desamparo se avolumam ante a 
desproteção. Em uma sociedade marcada por profundas disparidades de classe, raça/etnia e de gênero, é evidente que essa crise não atingirá todos(as) da mesma maneira: novamente, os segmentos mais pauperizados da classe trabalhadora, em geral negros e negras, LGBTQI +, serão aqueles que pagarão o preço mais alto. Para muitos, custou a própria vida ou a de seus familiares, mortos pela covid-19, pela fome ou pela violência decorrente desse caótico quadro social.

Desta forma, torna-se importante refletir sobre a dimensão social e política que a pandemia do novo coronavírus, a covid-19, exacerba: a lógica que tem sido reiterada na sociabilidade brasileira e assumida pelo Estado (ao demonstrar o seu papel como garantidor na dinâmica social tida como "normal", mas naturalmente desigual), que estabelece que alguns possuem mais chances de sobreviver e outros são abandonados à própria sorte (conforme conceito de necropolítica²), ou seja, algumas vidas são definidas como descartáveis.

O avanço da pandemia do novo coronavírus, a covid-19, denuncia a superficialidade e o mito do argumento "todos estamos juntos, pois o vírus é democrático e atinge todas as classes sociais" ao evidenciar as condições objetivas de vida na sociedade brasileira, desvelando facetas da violência estrutural. Portanto, impera desnaturalizar a violência para buscar formas de sociabilidade e de organização político-econômica em que todas as vidas humanas possam importar.

A leitura de realidade que se destaca no conjunto dos artigos desta edição que tratam desse período pandêmico e seus desafios é que não há amadorismo, equívocos ingênuos nem simples omissão gratuita: o que está ocorrendo é mais um conjunto orquestrado de ações que, combinadas ao momento pandêmico, tentam fazer avançar a lógica inexorável

2 A necropolítica é a política da morte adaptada pelo Estado. Não é um episódio, nem um fenômeno que foge à regra. É a regra. MBEMBE, A. Crítica da razão negra. São Paulo: n. 1 edições, 2018. 
de sustentação dessa ordem sociometabólica construída pelo capital. Para que isso ocorra, é fundamental destruir os parcos direitos conquistados pela classe trabalhadora, manter intacto o racismo, o machismo, o heteropatriarcalismo e a homofobia como pilares estruturantes da sociedade brasileira.

Problematizando o capitalismo pós-pandêmico, temos o artigo de Atílio Boron que apresenta as consequências do coronavírus para a economia mundial e, especialmente para nosso continente, na difícil conjuntura que vivemos. Com certeza, como aponta o autor, a ordem mundial do passado com suas "velhas formas de sociabilidades e organização da vida econômica já foram profundamente modificadas e o serão mais ainda quando a pandemia seja finalmente derrotada" colocando para o continente a necessidade de decisões cruciais.

Em relação ao Serviço Social, demandas à profissão e desafios postos na atual conjuntura são apresentados em quatro artigos contextualizados que buscam decifrar esses tempos de desigualdade e barbárie que se intensificam nas atuais formas de acumulação capitalista e resultam de mudanças no âmbito da reestruturação produtiva, associadas à nova hegemonia liberal-financeira, trazendo como consequências a precarização do trabalho e a radicalização da questão social.

Como se sabe, em especial nas últimas décadas, o capital financeiro assumiu o comando no processo de acumulação, de forma que o campo de sua acumulação não mais apresenta fronteiras de qualquer ordem (Marques, 2018, p. 11). Seu domínio sobre o capital produtivo traz consequências graves à "classe que vive do trabalho" com a manutenção de taxas elevadas de desemprego, insegurança e instabilidade nos empregos, crescimento do trabalho informal, redução de salários, precarização das relações de trabalho, incluindo terceirizações e contratos por prazos determinados, entre outros aspectos. Tal situação se agrava quando se fala de mulheres negras. 
No âmbito do mundo do trabalho, no texto de Silvia Tejadas e Maíz Junqueira, salienta-se a importância do trabalho coletivo. As autoras ressaltam que o próximo período será desafiador para os/as assistentes sociais que serão instados/as a agir na defesa dos direitos da população no acesso à justiça; nas disputas judiciais, em meio a tentativas de culpabilização e criminalização dos indivíduos pelas decorrências das desigualdades e da sociabilidade capitalista; no acesso a políticas públicas, em contexto de precarização, e de descontextualização da realidade.

No texto de Marcia Eurico, Renata Gonçalves e Tales Fornazier, os determinantes de etnia/cor, gênero e sexualidade são apresentados como determinantes dos processos de nossa formação socioeconômica e, assim, colocados em condição de centralidade para os profissionais de Serviço Social. Os/as autores/as ressaltam que uma sociedade livre de todas as formas de exploração e opressão só pode ser construída no campo das lutas sociais.

Raquel Soares, Maria Valéria Correia e Viviane dos Santos ressaltam que os profissionais de Serviço Social de todo o país têm lutado bravamente pela assistência à saúde da população em meio às contradições de uma política extremamente precarizada, desfinanciada e privatizada, instrumentalizada a serviço dos interesses do mercado privado da saúde. As autoras salientam que em face das contradições da pandemia, os/as assistentes sociais pautados/as no projeto ético-político-profissional foram capazes de propor respostas qualificadas às demandas complexas da crise sanitária e das expressões da questão social. Valeram-se de estratégias coletivas de reflexão sobre a realidade, articulações interna e externa aos serviços, inclusive em meio aos movimentos sociais, potencializando o tensionamento dos limites da relativa autonomia profissional, na defesa do Sistema Único de Saúde, da reforma sanitária e de uma sociabilidade emancipada. Enfim, na resistência pela vida de todos/as e contra a barbárie. 
Na mesma direção, cabe destacar o trabalho apresentado por Raquel Raichelis e Carola Carbajal que enfatiza, nesse contexto de interlocução profissão/pandemia do coronavírus, os impactos dessa condição no "mundo do trabalho cotidiano de assistentes sociais, cujo desvendamento deve ser remetido à crise estrutural do capital das últimas décadas e às suas estratégias de enfrentamento", âmbito no qual os grupos mais atingidos são os segmentos vulnerabilizados e periféricos das classes trabalhadoras, em razão das precárias condições de moradia, trabalho e vida que marcam seu cotidiano.

Nesse artigo, Raichelis e Carbajal retomam a questão da (nova) morfologia do trabalho, agora contextualizada no âmbito da pandemia, para deixar claro que a pandemia apenas exacerbou traços de uma grande crise que há quatro décadas configura o capitalismo contemporâneo.

Diversas são as questões colocadas para análise e enfrentamento da Pandemia do coranavirus e apresentados alguns desafios para o Serviço Social.

\section{Referências}

HARVEY, D. A política anticapitalista na era do COVID-19. Esquerda.net. Disponível em: https://www.esquerda.net/artigo/david-harvey-politica-anticapitalista-na-era-do-covid-19/66747. Acesso em: 6 dez 2020.

MANDEL, E. O capitalismo tardio. São Paulo: Abril Cultural, 1982.

MARQUES, Rosa Maria. O capitalismo financeiro e as políticas sociais: a nova face da contemporaneidade. In: A nova morfologia do Trabalho no Serviço Social. Organizado por RAICHELIS, Raquel; VICENTE, Damares e ALBUQUERQUE, Valéria. São Paulo, Cortez Editora, 2018.

MBEMBE, A. Crítica da razão negra. São Paulo: n. 1 edições, 2018.

MÉSZAROS, I. Para além do capital. São Paulo: Boitempo, 2002.

YAZBEK, M. C. et al. Revista Serviço Social \& Sociedade e os 80 anos do Serviço Social brasileiro: a marca da renovação. In: Serviço Social no Brasil. História de resistências e de ruptura com o conservadorismo. São Paulo: Cortez, 2016. 


\section{Sobre as autoras}

Maria Carmelita YazbeK - Assistente social. Doutora em Serviço Social. Professora e pesquisadora em Serviço Social.

E-mail: mcyaz@uol.com.br

Maria InÊs Bravo - Assistente social. Doutora em Serviço Social. Professora do quadro permanente da Pós-Graduação da Faculdade de Serviço Social da Universidade do Estado do Rio de Janeiro.

E-mail: msouzabravo@gmail.com

Maria Liduína de Oliveira e Silva - Coordenadora do Programa de Pós-Graduação em Serviço Social e Políticas Sociais. Docente do curso de Serviço Social. Assessora editorial da área de Serviço Social da Cortez Editora.

E-mail: liduoliveira90@gmail.com

MARIa Lúcia MARTINELli - Assistente social, doutora em Serviço Social, docente e pesquisadora em Serviço Social.

E-mail: mlmartinelli@terra.com.br 